\title{
Advances in surface markers of liver cancer stem cell
}

\author{
Jin-Liang Zhang', Lan-Qi Gong ${ }^{2,3}$, Qian Yan ${ }^{2,3}$, Ning-Ning Zhou ${ }^{4}$, Victor Ho-Fun Lee ${ }^{1,2}$, Xin-Yuan Guan ${ }^{2,3}$ \\ 'Department of Clinical Oncology Center, The University of Hongkong-Shenzhen Hospital, Shenzhen 518053, China. \\ 2Department of Clinical Oncology, The University of Hong Kong, Hong Kong, China. \\ ${ }^{3}$ State Key Laboratory for Liver Research, The University of Hong Kong, Hong Kong, China. \\ ${ }^{4}$ Department of Medical Oncology, Sun Yat-Sen University Cancer Center, State Key Laboratory of Oncology in South China; \\ Collaborative Innovation Center for Cancer Medicine, Guangzhou 510060, China.
}

Correspondence to: Prof. Xin-Yuan Guan, Department of Clinical Oncology, The University of Hong Kong, Room L10-56, Laboratory Block, 21 Sassoon Road, Hong Kong, China. Phone: 852-3917-9782. E-mail: xyguan@hku.hk

How to cite this article: Zhang JL, Gong LQ, Yan Q, Zhou NN, Lee VHF, Guan XY. Advances in surface markers of liver cancer stem cell. Hepatoma Res 2019;5:27. http://dx.doi.org/10.20517/2394-5079.2019.13

Received: 21 Feb 2019 First Decision: 10 Apr 2019 Revised: 16 May 2019 Accepted: 24 May 2019 Published: 23 Jul 2019

Science Editor: Jin-Lin Hou Copy Editor: Cai-Hong Wang Production Editor: Jing Yu

\begin{abstract}
Liver cancer stem cells (LCSCs), a small subpopulation that constitutes liver cancer heterogeneity, play a vital role in cancer initiation, invasion, recurrence, metastasis, and resistance to chemo-radiotherapy. It is believed that therapies targeting LCSCs can improve the efficacy of conventional chemotherapy and radiotherapy by completely eliminating tumors while preventing recurrence. Therefore, during last decades, numerous surface markers for LCSCs have been identified and characterized in many subtypes of liver cancer, especially in hepatocellular carcinoma (HCC). These well-recognized surface markers significantly promote the therapeutic efficacy that identifies, targets and destroys LCSCs. Meanwhile, there have been intensive studies that aim to investigate the molecular mechanism of how stemness contributes to liver cancer relapse, recurrence and resistance. However, liver cancer stemness seems to be regulated by a hierarchical organization and crosstalk of a wide variety of signaling pathways. Using individual or few LCSC surface markers may not be able to completely reveal the intrinsic stemness hierarchy. From an integrated perspective, understanding of recent advances in LCSC surface markers remains important and urgent. In this review, we concentrate on demonstrating the indispensable roles of LCSC surface markers in identification and characterization of multiple cancer stages including initiation, invasion, metastasis, resistance and highlighting the cutting-edge therapeutic strategies against cancer stem cells in HCC.
\end{abstract}

Keywords: Liver cancer, hepatocellular carcinoma, cancer stem cell, surface marker

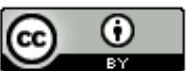

(C) The Author(s) 2019. Open Access This article is licensed under a Creative Commons Attribution 4.0 International License (https://creativecommons.org/licenses/by/4.0/), which permits unrestricted use, sharing, adaptation, distribution and reproduction in any medium or format, for any purpose, even commercially, as long as you give appropriate credit to the original author(s) and the source, provide a link to the Creative Commons license, and indicate if changes were made.

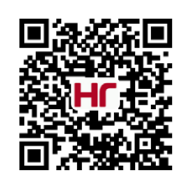




\section{INTRODUCTION}

Liver cancer is the seventh most frequently diagnosed cancer and the third death causing of cancer around the world, which has 841,080 newly diagnosed cases and caused 781,631 deaths in $2018^{[1]}$. Hepatocellular carcinoma (HCC) comprises $75 \%-85 \%$ of the primary liver cancer cases and intrahepatic cholangiocarcinoma and other rare types comprise $15 \%-25 \%{ }^{[1]}$. Chronic hepatitis B virus infection, hepatitis C virus infection, steatohepatitis and cirrhosis are the most prevalent precursors to HCC. Despite of the recent advances in liver cancer therapies, the current treatment cannot effectively prevent tumor recurrence and metastasis due to the existence of (liver cancer stem cells) LCSCs. The concept of cancer stem cells (CSCs) is raised from clinical and experimental observations that there exists a subpopulation of cancer cells that possess stem cell-like characteristics including self-renewal and differentiation that eventually lead to cancer relapse and resistance. LCSCs have been reported in varied types of HCC and are deemed to be one of the major causes of HCC recurrence, metastasis, chemoresistance and radioresistance.

Conventional therapies against non-stem liver cancer cells such as chemotherapy and radiotherapy, have multiple limitations that result in cancer recurrence and metastasis due to acquired resistance. The survival LCSCs can re-initiate tumor development and invasion [Figure 1]. Hence, in order to develop feasible therapies that can prevent tumor recurrence and metastasis, it is important to specifically identify, target and eliminate LCSCs. Recent advances in LCSC surface markers and understanding of cellular features related to LCSC phenotypes greatly improve the efficacy of treatments that target LCSCs. Targeting the LCSCs with high expression of certain stemness surface markers, can manipulate the abilities of LCSCs in proliferation, growth, maintenance, differentiation, resistance and apoptosis via cellular signaling pathways so that tumor regeneration can be impeded.

In order to develop patient-specific therapies that target LCSCs, multiple stemness surface markers have been identified consisting CD $133^{[2]}, \mathrm{CD} 44^{[3]}, \mathrm{CD}_{90}{ }^{[4]}$, epithelial cell adhesion molecule $(\mathrm{EpCAM})^{[5]}, \mathrm{CD} 47^{[6]}$, $\mathrm{CD} 34^{[7]}, \mathrm{C}-\mathrm{kit}^{[8]}, \mathrm{CD} 13^{[0]}, \mathrm{CD} 24^{[10]}$, calcium channel $\alpha 2 \delta 1$ isoform $5^{[11]}$, oval cell marker OV6 ${ }^{[12]}$, DLK $1^{[13]}$, $\mathrm{K}_{19}{ }^{[14]}$, and $\operatorname{Lgr}{ }^{+[15]}$ [Table 1]. The integrated therapy using conventional anti-carcinogenic inhibitors such as sorafenib with LCSCs-targeting drugs, may provide an effective therapeutic strategy for complete elimination of liver cancer.

\section{CD133}

CD133, also referred to as PROM1, is a member of prominin family that has a structure of five transmembrane single-chain glycoprotein with a molecular weight of $115 \sim 120 \mathrm{kDa}$, including an extracellular N-terminus, two large extracellular loops, two small intracellular loops and an intracellular C-terminus ${ }^{[16-19]}$. CD133 was originally identified as a surface marker of hematopoietic stem cells ${ }^{[16]}$. In solids tumor, CD133 was firstly identified and further isolated in brain tumors ${ }^{[20]}$. Later, the role of CD133 as a surface marker of CSC is been reported in a wide variety of tumor tissues such as lung cancer ${ }^{[21]}$, stomach carcinoma ${ }^{[22]}$, pancreatic cancer $^{[23]}$, colon cancer ${ }^{[24]}$, and liver cancer that was identified by our team ${ }^{[25-27]}$.

In 2006, Suetsugu et al.$^{[28]}$ reported that CD133+ liver cancer cells, sorted from the Huh7 cell line, exhibited a more potent capability of proliferation and metastasis compared to the CD133- counterparts. Our previous study indicated that CD133+ cells also processed a stronger cology-forming characteristic, greater tumorigenicity and potential to differentiate into angiomyogenic-like lineages ${ }^{[2]}$. We also further characterized the liver CD133+ CSCs, revealing that CD133+ cells were endowed with high in vivo tumorigenicity and the capability to form spheroids with an upregulated expression of stemness-associated genes in vitro ${ }^{[29-31]}$. Liu et al. ${ }^{[32]}$ reported that CD133 was crucial to monitor the migratory capability of LCSCs, tumor-initiating properties, and the epithelial-mesenchymal transition (EMT) process. Tang et al. ${ }^{[33]}$ demonstrated that CD133+ liver tumor-initiating cells (TICs) had angiogenesis ability. In addition, Li et al ${ }^{[34]}$ and other researchers ${ }^{[35]}$ also found that CD133+ HCC cells could exploit autophagy to maintain their survival. Liver CD133+ CSCs are 


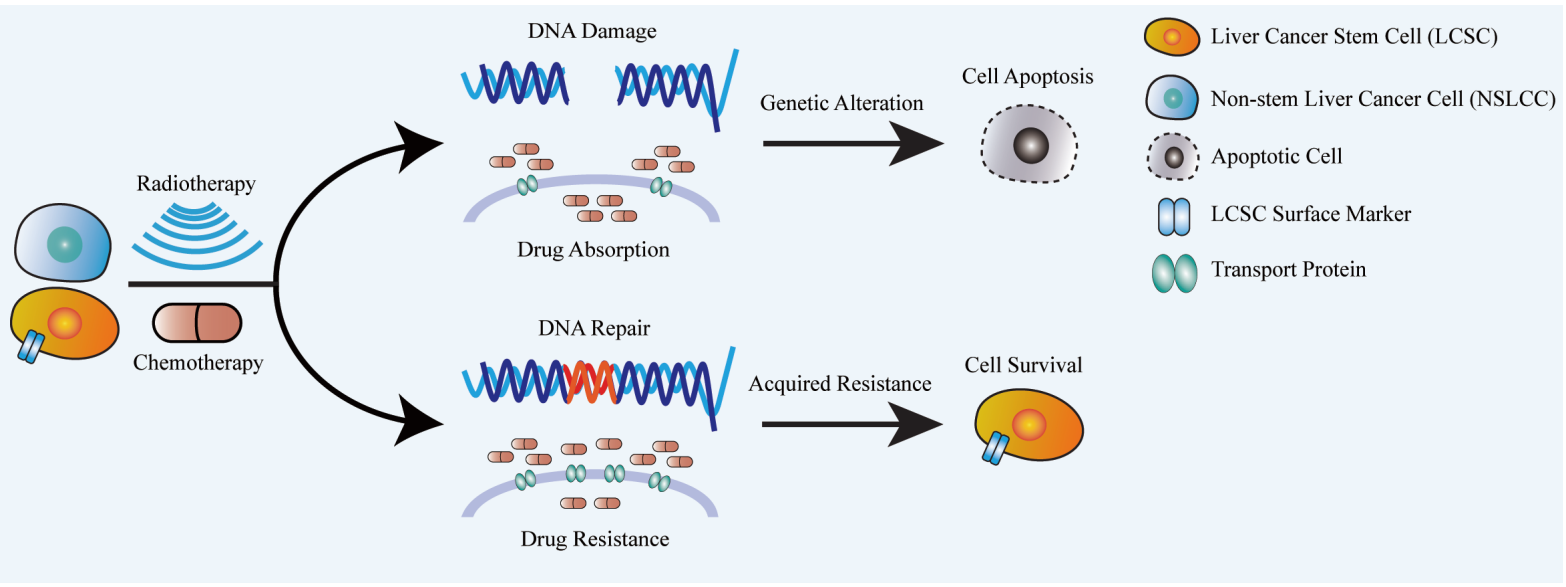

Figure 1. Acquired chemo- and radioresistance in liver cancer stem cells. Traditional chemo-/radiotherapy can induce genetic alteration in non-stem liver cancer cells (NSLCCS) via DNA damage and cytotoxic agent intake, in order to activate cellular apoptosis. However, upon treated with traditional chemo-/radiotherapeutic agents, liver cancer stem cells (LCSCs), can acquire chemo-/radioresistance including an increased level of drug intake and an enhanced DNA repairing mechanism, which eventually lead to a higher survival rate of LCSC subpopulation.

Table 1. Summary of liver cancer stem cell biomarkers and related pathways

\begin{tabular}{|c|c|}
\hline Surface markers of LCSCs & Related pathways \\
\hline CD133 & 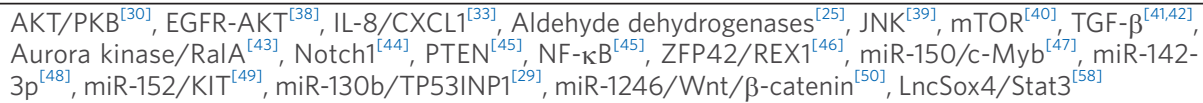 \\
\hline CD44 & $\mathrm{AKT}^{[81]}, \mathrm{YAP} / \mathrm{TEAD}^{[82]}$, anti-miR-27a/QD-HA-PEI ${ }^{[84]}$, TGF $\beta I / A L K 5^{[85]}$, mTOR ${ }^{[86]}$, FoxM1/ROS ${ }^{[83]}$ \\
\hline CD90 & $\mathrm{SHH} / \mathrm{Gli}$ and IL6/JAK2/STAT3 ${ }^{[91]}$, ABCG2 and Oct5 ${ }^{[93]}$, miR-125a/b $\mathrm{b}^{[96]}$, has $0067531^{[97]}$ \\
\hline EpCAM & 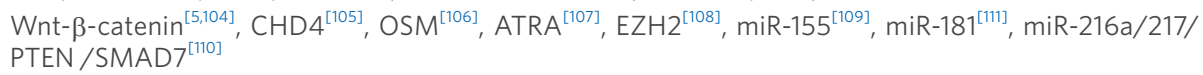 \\
\hline CD47 & $\mathrm{CTSS} / \mathrm{PAR2} 2^{[6,120]}, \mathrm{NF}-\kappa \mathrm{B}^{[122]}, \mathrm{SIRP} \alpha^{[119]}$ \\
\hline CD34 & OCT4, SOX2, NAONG, KIf4, c-Myc, and Lin2 $8^{[7]}$ \\
\hline C-kit & TGF- $\beta /$ SMAD2 and c-KIT/JAK1/STAT3 ${ }^{[132]}$ \\
\hline CD13 & TGF- $\beta$-/EMT ${ }^{[139]}$ \\
\hline CD24 & STAT3/NANOG ${ }^{[10,144]}$, Twist $^{[144]}$ \\
\hline$\alpha 2 \delta 1$ & OCT4, SOX2, NANOG, and BMI1 ${ }^{[11]}$, miR-31/ISL1 $1^{[148]}$ \\
\hline OV6 & Wnt/ $\beta$-catenin ${ }^{[12]}$ \\
\hline DLK1 & Nanog, SMO, SOX2, Oct3/4 ${ }^{[153]}$ \\
\hline K19 & EMT and TGFb/Smad ${ }^{[14,155]}$, PDGFR $\alpha$-laminin ${ }^{[156]}$, MET-ERK1/2-AP1 and SP1 ${ }^{[157]}$ \\
\hline LGR5 & HGF/ Rspo1 ${ }^{[173]}$, LSD1/Prickle1/APC/ $\beta$-catenin ${ }^{[175]}$ \\
\hline
\end{tabular}

shown to be more resistant to radiotherapy ${ }^{[36]}$ and chemotherapy ${ }^{[37]}$. Our previous study found that CD133+ cancer stem cells conferred chemoresistance caused by abnormal activation of the Akt/PKB pathway ${ }^{[30]}$. Other Aberrant signaling pathways related to CD133+ LCSCs have also been reported and characterized including EGFR-AKT ${ }^{[38]}, \mathrm{IL}_{-} 8 / \mathrm{CXCL1}^{[33]}$, aldehyde dehydrogenases ${ }^{[25]}, \mathrm{JNK}^{[39]}, \mathrm{mTOR}^{[40]}, \mathrm{TGF}-\beta^{[11,42]}$, aurora kinase/RalA pathway ${ }^{[43]}$, Notch1 signaling pathway ${ }^{[44]}$, PTEN signaling pathway ${ }^{[45]}$, NF- $\kappa B$ signaling pathway ${ }^{[45]}$. Recently, our team identified ZFP42/REX1 as a key regulator of cancer stemness in CD133+ LCSCs by genome-wide DNA methylation analysis ${ }^{[46]}$. A panel of miRNAs that include miR-150, miR-142-3p, miR-152, miR-130b and miR-1246 have also been found to regulate proliferation, tumorigenicity, invasion, migration and angiogenesis in CD133+ HCC cells ${ }^{[29,47-50]}$.

In summary, aforementioned studies demonstrate that the maintenance of CD133+ LCSCs is modulated by an intricate network of signaling pathways. Cells with varied morphological structures primarily constitute HCC and express distinct hepatic lineage genes. Thereby, there might also be functionally different cancer cell subpopulations that express distinct stemness-associated markers. Wilson et al.$^{[51]}$ have shown that the 
most widely used CSC markers including CD133, CD44, CK19, CD90, EpCAM, and ALDH are not specific to LCSCs. CD133+/ALDH+ cells showed to possess stronger tumorigenicity than their CD133-/ALDH- or CD133-/ALDH+ counterparts ${ }^{[25]}$. We also found and confirmed ${ }^{[30]}$ that CD133+/ALDH+ cells possess stronger tumorigenicity than their CD133-/ALDH- and CD133-/ALDH+ counterparts both in vivo and in vitro. Furthermore, we established a hierarchical organization in HCC to demonstrate HCC tumorigenicity from the highest to the lowest: CD133+/ALDH+ > CD133+/ALDH- > CD133-/ALDH-. Zhao et al ${ }^{[11]}$ reported that some subpopulations of liver cancer cells, including CD133+/1B50-1+, CD13+/1B50-1+ and EpCAM+/1B50-1+ cells, exhibited high tumorigenicity. CD133+/EpCAM+ cells displayed the highest tumor-initiating activity, compared to CD133+/EpCAM- and CD133-/EpCAM+ cells ${ }^{[52]}$. Elevated CD133 expression is associated with tumor differentiation grades, disease stages and alpha-fetoprotein (AFP) levels. Furthermore, a higher CD133 expression level indicates higher recurrence rates as well as poorer overall survival ${ }^{[3,53-57]}$. Recently, Chen et al. ${ }^{[58]}$ reported that a long noncoding RNA termed LncSox4, is upregulated in CD133 and EPCAM high-expressed HCC tissues, modulating the self-renewal of liver tumor-initiating cells via Stat3-mediated Sox4 expression.

When CD133 as a target was concerned, Sasaki et al. ${ }^{[54]}$ developed a DC-based vaccine inhibited the tumorigenicity of CD133+ HCC cells subcutaneously injected into nude mice. Our previous study demonstrated that AKT1 inhibitor can significantly reduce the expression of the survival proteins that was primarily expressed endogenously in CD133+ HCC cells ${ }^{[30]}$. Smith et al. ${ }^{[59]}$ developed an anti-CD133 antibody-drug conjugate that could inhibit growth of CD133+ HCC cells. Lang et al ${ }^{[60]}$ prepared a 131ICD133 monoclonal antibody $(\mathrm{mAb})$ with specific selectivity that could lead to clinical significance in liver cancer treatment. Huang et al.$^{[61]}$. developed an bispecific antibody (BsAb) of anti-CD3/anti-CD133 and coagulate it to the cytokine-induced killer (CIK) cells to effectively target and kill CD133+ cells.

\section{CD44}

CD44, firstly was recognized as a lymphocyte homing receptor ${ }^{[62]}$, can be broadly detected in multiple tissues including embryonic ${ }^{[63]}$, hematopoietic ${ }^{[64]}$, mesenchymal ${ }^{[65]}$, and cancer stem cells ${ }^{[66-69]}$. In humans, CD44 gene comprises 20 exons and 19 introns and undergoes complicated alternative splicing to generate CD44 standard form $(\mathrm{CD} 44 \mathrm{~s})^{[70-72]}$ and $\mathrm{CD} 44$ variant splice isoforms ${ }^{[73]}$. CD44 is involved in the interaction between cells and extracellular matrix ${ }^{[7]}$.

Williams et al ${ }^{[75]}$ emphasized on the behavior of CD44-regulating stem cell, including cell differentiation and self-renewal and cell-matrix interactions during tumor progression and migration. Isolated CD44s+ cells can effectively form colonies and possess hepatic markers ${ }^{[7]}$. In HCC, CD44s expression is involved to modulation of the mesenchymal phenotype mediated by TGF-beta and its expression level is an unfavorable prognosis factor ${ }^{[77]}$. Proliferation of $\mathrm{CD} 44+$ cells and its tumorigenesis can be stimulated by IL6 produced by tumor-associated macrophages $(\mathrm{TAMs})^{[78]}$. CD44 expression is known to be related to invasive and metastatic behavior of liver cancer ${ }^{[79]}$. For instance, FAM83D promotes HCC recurrence by increasing CD44 expression and modulating CD44+ CSCs malignancy ${ }^{[80]}$. Coexpression of CD44 with other markers such as CD133 and CD9o help well identify LCSC phenotypes. CD133+/CD44+ subpopulation is associated with the metastatic capability in the xenotransplantation assay in nude mice ${ }^{[36]}$. CD133+/CD44+ HCC cells exhibits elevated expression of many CSC-related genes and are more chemotherapy-resistant owing to the increased expression of transporters that belong to ATP-binding cassette superfamily ${ }^{[79]}$. Most of CD90+ cells coexpress CD44 and these CD90+/CD44+ cells exhibit an aggressive behavior than the CD90+/CD44- counterpart and easily develop metastases in the nude mice lung ${ }^{[4]}$. Yang et al ${ }^{[4]}$ found that administration of anti-CD44 antibody was able to induce apoptosis of the CD90+ and CD90- cells in a dose-dependent manner, and prevented CD90+/CD44+ CSC-derived tumor both locally generated and distantly metastasized ${ }^{[4]}$. 
The mechanism of the conversion from terminally differentiated cells that expose to oncogenic factors into CSCs remains largely uninvestigated. Dhar et al..$^{[81]}$ explained this phenomenon that CD44 could activate AKT to induce Mdm2 phosphorylation nuclear translocation, which terminated the p53 DNA-damage surveillance. This process enables DNA- sequestered hepatocytes to avoid p53-induced apoptosis and to respond to proliferation-related signals that promotes daughter cells transfer to HCC progenitors. CD44s, regulated by the YAP1/TEAD axis, can positively modulate the YAP1 expression along with its target genes through the PI3K/Akt pathway in HCC. This processes composed a feedback loop consisting of CD44s and YAP1, promoting HCC tumorigenesis by regulating cell proliferation and invasion during ${ }^{[82]}$. Kopanja et al. ${ }^{[83]}$ find that FoxM1 expression level is associated with CD44 expression, suggesting that FoxM1 is required for the expression of CD44 in HCC cells. In liver cancer, anti-miR-27a/QD-HA-PEI exhibit effective anti-cancer effects in vitro and in vivo via down-regulation of FOXO1 and PPAR- $\gamma^{[84]}$. Galunisertib (LY2157299), a selective ATP-mimetic TGF- $\beta$ inhibitor, can effectively reduce tumor cell vitality via alleviating expression of CD44 and $\mathrm{THY}_{1}{ }^{[85]}$. INK128, an ATP-competitive mTOR inhibitor, can suppress CD44+ and sorafenib insensitive HCC in vitro and in vivo ${ }^{[86]}$.

\section{CD90}

In 1964, CD90 was initially named as $\theta$ antigen because it had identified in a process to develop an antileukemia xeno-antibody in $\mathrm{CH} 3$ AKR strain mice ${ }^{[87]}$. Later in 1969, $\theta$ antigen was renamed as Thy-1 since the thymus was found to the location where precursors of T cells got mature ${ }^{[88]}$. In the 1980s, Ades et al ${ }^{[89]}$ isolated CD90 from MOLT-3, a human T-cell leukemia cell line, demonstrated the presence of CD90 in human. CD90 is a 25-37 kDa glycosylphosphatidylinositol-anchored glycoprotein, and a crucial modulator of multiple cellular events, including immunologic function of promoting $\mathrm{T}$ cell activation and nonimmunologic functions such as nerve regeneration, tumorigenesis, metastasis, inflammation, and fibrosis ${ }^{[90]}$. The CD90+ LCSCs isolated from liver cancer tissue specimens shows a strong tumorigenic potential after being implanted into nude mice ${ }^{[4]}$. Zhang et al.$^{[91]}$ illustrated that by activating the IL6/JAK2 pathway, SHH/Gli could regulated the stemcell like characteristics of CD90+ LCSC. Cytotoxic drugs 5-FU or epirubicin treatment result in the generation of CD90+ and CD105+ cells in vitro in Huh1 and Huh7 cells, which primarily have no CD90+ nor CD105+ cells $^{[92]}$. It was shown by Jia et al. ${ }^{[93]}$ that being as a closely related cause to chemoresistance, the overexpression of ABCG2 and Oct5 was frequently enriched in CD90+/CD133+ LCSCs. Subcutaneous transplantation of CD90+/CXCR4+ HCC cells to NOD/SCID mice are easily detected in the peripheral blood and able to develop distal metastatic tumors ${ }^{[9]}$. The expression of $\mathrm{CD} 90+$ does not overlap with the expression of EpCAM+. Gene expression analysis shows that EpCAM+ cells display epithelial characteristics, while CD90+ cells exhibit a vascular endothelial type of gene profile ${ }^{[95]}$. Exosomes containing miR-125a and miR-125b derived from TAMs mediate stem cell properties in HCC by targeting CD90 ${ }^{[96]}$. Zhang et al. ${ }^{[97]}$ demonstrated that has 0067531 affected the biological functions of CD90+ HCC cells by regulating P13K-AKT signaling pathway. Moreover, CD90 overexpression is shown to be associated with unfavorable prognosis ${ }^{[98]}$. Overall, the results of present studies have suggested that $\mathrm{CD} 90$ is a potential biomarker for HCC diagnosis and targeting therapy.

\section{EpCAM}

EpCAM is the first human tumour-associated antigen identified with monoclonal antibodies $(\mathrm{mAb})^{[99]}$, and also the first monoclonal antibody manufactured against for human cancer is murine $\mathrm{mAb} 17-1 \mathrm{~A}$ targeting $\mathrm{EpCAM}^{[100,101]}$. According to an early elaborate review about EpCAM in cancer ${ }^{[102]}$, it is a type I membrane protein of 314 amino acids, containing two epidermal growth factor-like domains at the extracellular domain and 26 amino acids at intracellular domain. EpCAM is a cell surface marker expressed in almost all the epithelial tumors ${ }^{[103]}$. The EpCAM+ HCC cells possess CSC-like characteristics including an enhanced self-renewal ability and differentiation potential, and are able to initiate the development of highly tumorigenic cancer in NOD/SCID mice. EpCAM is a target gene in Wnt- $\beta$-catenin signaling pathway ${ }^{[5,104]}$. Chemoresistance as well as stemness of EpCAM+ LCSCs are modulated by abnormal expression of CHD $4^{[105]}$, 
$\mathrm{OSM}^{[106]}$, ATRA ${ }^{[107]}, \mathrm{EZH}_{2}{ }^{[108]}$. A group of microRNAs including miR-181, miR-155, miR-181, miR-216a/217 have been found involved in regulating stemness of EpCAM+ HCC cells ${ }^{[109-111]}$. Patients with EpCAM+l AFP+ HCC have higher frequency of portal vein invasion and significantly shorter survival than EpCAM-/ AFP- HCC patients ${ }^{[112]}$. Chen et al. ${ }^{[113]}$ proposed a novel EpCAM-antibody-labeled polymer in nano-vesicles for cancer stem cells-targeted drug and siRNA and displayed higher tumor selectivity and killing efficacy. A recent study revealed that metformin decreased both the EpCAM+ HCC cells abundance and self-renewal capability ${ }^{[114]}$. Babaei et al. ${ }^{[115]}$ reported that EpCAM targeted nanoparticles of PEG-Au@Si-5-FU exhibited higher cytotoxicity than nontargeted PEG-Au@Si-5-FU in 2D and 3D HepG2 cell cultures. Many EpCAM antibodies are currently available to treat patients with EpCAM+ malignant ascites in preclinical and clinical trials including edrecolomab, adecatumumab, MT110 and catumaxomab ${ }^{[16]}$.

\section{CD47}

CD47 is firstly discovered in 1992 as a surface protein that is frequently expressed in ovarian carcinoma ${ }^{[117]}$. Later studies have exhibited that $\mathrm{CD} 47$ is a highly expressed transmembrane protein with various functions ${ }^{[118,119]}$. Lee et al. ${ }^{[6]}$ identified that $\mathrm{CD} 47$ was preferentially expressed in liver TICs, which result in cancer development, self-renewal, metastasis and chemoresistance and significantly influence the clinical prognosis of patients. CD47+ HCC cells preferentially secret cathepsin S (CTSS), which manipulates liver TICs through the CTSS/protease-activated receptor 2 (PAR2) loop. Suppression of CD47 by morpholino decreases HCC viability and exerts a chemo-sensitization effect through blockade of CTSS/PAR2 signaling pathway $^{[6,120]}$. Increased CD47 expression level has been considered as a negative prognostic factor for a wide variety of cancer ${ }^{[118,121]}$. Lee et al. ${ }^{[6]}$ unraveled that $\mathrm{CD} 47$ expression was enriched on CD133+/CD24+ TICs isolated from a HCC cell line and was increased by serial passage in the presence of doxorubicin and cisplatin, and high CD47 expression conferred chemoresistance and increased the stemness characteristics of TICs. CD47 blockade or down-regulation suppresses HCC development and elevated sensitivity to chemotherapeutic drugs such as sorafenib ${ }^{[6,122-124]}$, while NF- $\kappa B$-mediated $\mathrm{CD} 47$ up-regulation enhances sorafenib resistance ${ }^{[122]}$. Importantly, not only being considered as a LCSC surface marker, expression of CD47 is also involved in innate immune response ${ }^{[123]}$. CD47 is a ligand for signal regulatory protein- $\alpha$ (SIRP $\alpha$ ), which expressed on macrophages and dendritic cells ${ }^{[125]}$. After binding CD47, SIRP $\alpha$ activates a signaling cascade that leads to the inhibition of phagocytosis ${ }^{[119]}$. Macrophage phagocytosis of HCC cells is enhanced after treatment with CD47 antibodies (CD47mAbs) that impede CD47 binding to SIRP $\alpha^{[118,126]}$. Treatment to mice with tumor burden with antibodies that blockade CD47 signaling can produce intensive tumor regression when used solely or integrated with existing therapeutic strategies ${ }^{[118,121,127,128]}$ and humanized CD47 antibodies have recently entered human clinical trials (NCT02678338, NCT03717103, NCT03763149, NCT02216409, NCT02367196).

\section{CD34}

Park et al.${ }^{[7]}$ identified CD 34 + as a newfound LCSC surface marker. SOX2 is one of the vital factors maintaining CD34+ LCSC stemness before colonization, and OCT4, SOX2, NAONG, Klf4, c-Myc, and Lin28 are supposed to be associated with stemness maintenance of CD34 + LCSC on feeder cells $s^{[7]}$. Park et al.$^{[129]}$ found that CD34+ LCSCs possessed stemness characteristics and three types of liver carcinomas were directly produced from CD34+ PLC/PRF/5 hepatoma cells (PLC): hepatocellular carcinoma (HCC), cholangiocarcinoma (CC), as well as combined hepatocellular cholangiocarcinoma (CHCs). CD34+ PLCs that express OV6 and their progeny $\mathrm{OV} 6+$ cells primarily produce $\mathrm{CHC}$ and $\mathrm{CC}$, suggesting that the OV6+ antigen is correlated with human $\mathrm{CHC}$ and $\mathrm{CC}^{[129]}$. Crosby et al. ${ }^{[130]}$ addressed that c-kit+ or CD34+ liver cancer cells had the potential to transfer to biliary epithelial cell lineage and might represent biliary epithelial stem cells. Zeng et al ${ }^{[131]}$ demonstrated that CD34+ LCSCs and xenografts generated by CD34+ LCSCs exhibited a blended phenotypes, coexpressed stemness and myelomonocytic cell markers. CD34+ LCSCs are often coexpressed with CD45, suggests that the origin appears to be from a hematopoietic precursor, which illuminate a comprehensive understanding of the molecular mechanism of how LCSCs are originated and developed ${ }^{[131]}$. 


\section{C-kit}

C-kit, also named as stem cell factor receptor, is a receptor protein of transmembrane type III with intrinsic tyrosine kinase activities to generate human embryonic stem cells. Besides having been used to identify human hematopoietic progenitor cells or hepatic stem cells, c-kit also is capable to sustain the stem cells in an undifferentiated state. The presence of c-kit on HCC cell lines suggests that stem cell factor (SCF) have been considered to play an indispensable role in the manipulation of the proliferative capability of liver cancer cells $^{[8]}$. Fujio et al ${ }^{[132]}$ demonstrated that C-kit could be an important factor in the receptor systems, a growth factor related to the biological functions of liver stem cells and the development of bile ducts. It has been reported $^{[133]}$ that TGF- $\beta / \mathrm{SMAD} 2$ signaling pathway mediates the expression of the $\mathrm{c}-\mathrm{KIT}$ receptor ligand in a transcriptional level by activating c-KIT/JAK1/STAT3 signaling pathway. SCF activates TGF- $\beta 1$ ligand expression through STAT3, thereby result in a positive feedback loop between TGF- $\beta / S M A D$ and SCF/c-KIT signaling pathway. The signaling network attenuates TGF- $\beta$-mediated cell cycle arrest and activates tumor cell to into proliferation, epithelial-to-mesenchymal-transition, migration, and invasion ${ }^{[133]}$. Blockade of C-kit in late cirrhosis might restore TGF- $\beta$ inhibitory effect on normal liver stem cells and prevent initiation and progression of $\mathrm{HCC}^{[134]}$. The expression of C-kit is significantly higher in liver cancer patients with advanced clinical stage and is an independent poor prognostic factor of DFS in HCC patients ${ }^{[135]}$.

\section{CD13}

CD13, also referred as aminopeptidase $\mathrm{N}$, is a membranous glycoprotein that has been used to identify leukemia or lymphoma cells ${ }^{[136]}$. CD13 plays vital roles in cancer progression including cell proliferation, invasion, and angiogenesis ${ }^{[137-139]}$. Nagano et al. ${ }^{[140]}$ demonstrated that CD13 is a surface marker of CSCs in human liver cancer and may have promising therapeutic potentials. It was found by Haraguchi et al..$^{[9]}$ that CD13 attenuated ROS-induced DNA injury after chemo/radiation treatment and protected cells from apoptosis. They also found that ubenimex, a CD13 inhibitor, alleviated oncogenic and self-renewal ability of CSCs and suppressed CD13+ tumor growth with co-treatment of 5-FU. Kim et al ${ }^{[141]}$ reported that upregulated CD13 expression was associated with TGF- $\beta$-induced EMT-like process, which prevents further increasing of ROS level as well as the induction of apoptosis, supporting the survival of CD13+ CSCs in liver cancer cells. It was also shown by Yamashita et al ${ }^{[142]}$ that ubenimex synergistically enhanced the antitumor effects of a chemotherapy regimen composed of 5-FU, CDDP and DXR on HCC cells, and the functions of ubenimex were associated with enhanced intracellular ROS levels.

\section{CD24}

CD24 is a glycosylated and mucin-like cell surface glycoprotein with relatively high expression in stem/ progenitor cells and related to formation and development of CSCs isolated from breast, colon, ovary, pancreas ${ }^{[143,144]}$. Huang et al. ${ }^{[145]}$ firstly cloned the full-length CD24 cDNA sequence from human HCC cells and identified that CD24 mRNA overexpression was associated with p53 mutation and tumor differentiation. Lee et al.$^{[10]}$ reported CD24 as a surface marker of LCSCs. They ${ }^{[10]}$ also documented that CD24 was upregulated in chemoresistant tumors after cisplatin treatment in immunodeficient mice model. Significantly, CD24 expression largely overlaps with expression of CD133 and EpCAM in $\mathrm{HCC}^{[10]}$. CD24+ HCC cells have a great impact on clinical prognosis of patients, and play a vital role in self-renewal, differentiation, maintenance, and metastasis of tumors ${ }^{[10]}$. Self-renewal and tumor initiating behavior of CD24+ LCSCs is regulated by STAT3-mediated NANOG regulation ${ }^{[10]}$. It was demonstrated by Liu et al. ${ }^{[146]}$ that the pathway of Twist2CD24-STAT3-NANOG was crucial to the regulation of self-renewal of CD24+ LCSCs.

\section{$\alpha 2 \delta 1$}

In 2010, García et al ${ }^{[147]}$ reported that when the expression of calcium channel $\alpha 2 \delta 1$ subunit was inhibited, migration, adhesion as well as spreading of myoblasts were impaired, whereas the L-type calcium maintained unaffected, suggesting a newfound function of the $\alpha 2 / \delta 1$ subunit in extracellular signaling. Later studies 
have confirmed that calcium channel $\alpha 2 / \delta 1$ subunit is a potential marker for CSCs in laryngeal squamous cell carcinoma ${ }^{[148]}$ and in non-small cell lung cancer ${ }^{[149]}$. Zhao et al.$^{[1]]}$ identified $\alpha 2 / \delta 1$ subunit as a LCSCs marker and developed its monoclonal antibody named 1B50-1, which had positive therapeutic effects on HCC xenograft by eradicating LCSCs. $\alpha 2 / \delta 1+$ liver cancer cells have stemness characteristics, including the expression of stemness-related genes such as SOX2, OCT4, BMI1, and NANOG, the capability of selfrenewal, invasiveness, and to produce both $\alpha 2 / \delta 1+$ and $\alpha 2 / \delta 1-$ cells $^{[11]}$. Recently, Zhang et al ${ }^{[150]}$ discovered that miR-31 could negatively manipulate the self-renewal capability of $\alpha 2 / \delta 1+$ LCSCs via sequestering ISL1, implying a potential therapeutic strategy for directly targeting liver TICs.

\section{OV6}

1998, Roskams et al ${ }^{[151]}$ identified that reactive ductules and intermediate hepatocyte-like cells originated partially from differentiation and activation of progenitor cells. It has been put forward that OV6 in human liver can help identify cells owing a progenitor stem cell-like characteristics, which has the ability to differentiate into OV6+ ductular cells or lobular hepatocytes. OV6+ is a specific phenotype of oval cells that has been originally identified in the livers of tumor transplanting rats, and is identified as a surface marker of human liver progenitor cells in $2008^{[152]}$. In 2012, Yang et al.$^{[12]}$ further demonstrated that OV6+ HCC cells not only possessed a stronger capacity to form spheroids, but also showed stronger tumorigenic and metastatic characteristics. These results suggest that OV6+ HCC cells are highly capable of self-renewal and forming tumors. Wnt $/ \beta$-catenin signaling plays an indispensable role in the induction and expansion of OV6+ subpopulation within tumor tissues. Thereby, OV6 is considered as an effective LCSCs surface marker. Additionally, Yang et al. ${ }^{[12]}$ also demonstrated that overexpression of OV6 enhanced the invasive and metastatic characteristics of HCC CSCs so that the number of OV6+ CSCs increased in patients diagnosed with liver cancer indicated poorer clinical outcomes and prognosis.

\section{DLK1}

DLK1 has shown to be expressed in fetal liver, but scarcely expressed in neonatal and adult liver in mice and rats ${ }^{[153]}$. Huang et al ${ }^{[154]}$ demonstrated that proliferation of SMMC-7721 cells was significantly enhanced by exogenous DLK1, whereas colony-forming ability, cell growth, and tumorigenicity of Huh-7, Hep3B, and HepG2 cells were significantly impeded by the suppression of endogenetic DLK 1 via RNA interference. It was identified by Li et al ${ }^{[13]}$ that the enhancing effect of DLK1 in tumourigenicity and cancer stemness could potentially be used as a molecule target for therapies against LCSCs. DLK1+ cells have been discovered in all 17 HCC cell lines and showed a more potent capability of clonogenicity in vitro and tumorigenicity in animal models. In addition, some stemness markers have been identified upregulated in DLK1+ Huh-7 and Hep3B cells including NANOG, SMO, SOX2, Oct3/4, CD133, CD90, and EpCAM. The isolated DLK1+ HCC cells are possess strong therapeutic resistance to conventional cytotoxic agents such as doxorubicin, cisplatin, epirubicin, and $5-\mathrm{FU}^{[155]}$.

\section{K19}

Cytokeratin $19(\mathrm{~K} 19)$ is a newfound CSC surface marker associated with EMT and TGFb/Smad signaling pathway ${ }^{[14]}$. K19 disappears from liver cells but remains in bile duct cells at the 10th differentiation week, which is an important step in the organogenesis of liver ${ }^{[156]}$. It has been reported that using 18 F-FDGPET and CYFRA 21-1 can identify K19+ LCSCs in HCC. In patients with HCC, K19 expression is significantly correlated with GLUT1 expression and FDG accumulation, and K19 regulated 18F-FDG uptake via TGFß/ Smad signaling pathway ${ }^{[157]}$. Besides the TGFb/Smad signaling pathway, many other signaling pathways have been documented as well. The PDGFR $\alpha$-laminin B1-K19 cascade drives tumor development at the invasive front of $\mathrm{HCC}^{[158]}$. Rhee et al. ${ }^{[159]}$ reported that expression of K19 in HCC is modulated by fibroblast-derived HGF via a MET-ERK1/2-AP1 and SP1 axis. K19+ cells have high proliferation potential and doxorubicin, 5-fluorouracil and sorafenib resistance ${ }^{[14,160]}$. K19 expression exhibits strong correlation with increased 
tumorigenicity, decreased tumor differentiation potential, metastasis and invasion and poor prognosis in $\mathrm{HCC}^{[160-163]}$, with profiling study shows that K19+ HCCs highly express invasion or metastasis-related genes (TACSTD2,VASP, LAMC2, LAMB1, PDGFRA), biliary/HPC markers (NOTCH2, GSTP1, CD133, JAG1) and members of the miRNA-200 family (miR-200c, miR-141) ${ }^{[160]}$. A recent study showed that K19+ cells were not involved in the early clonal expansion of rat hepatocarcinogenesis, and K19 expression arose in preneoplastic hepatocyte lesions undergoing malignant transformation. In addition, they also indicated that K19 positivity in HCCs did not necessarily reflect the cell of origin of the tumor, but rather the plasticity of preneoplastic cells during the tumorigenic process ${ }^{[164]}$.

\section{LGR5}

In 2007, LGR5, a G protein-coupled receptor with a seven transmembrane domains ${ }^{[165]}$, was firstly identified as a surface marker of intestinal stem cells ${ }^{[166]}$. Later, it has been applied to identify homeostatic stem cells in various organs such as ovaries, hair follicles, mammary gland, and stomach ${ }^{[166-169]}$. LGR5 has been reported to involved in regeneration of damaged tissues in the small intestine and colon, liver, pancreas, and stomach ${ }^{[15,170-172]}$ and in CSCs that regulates tumor proliferation ${ }^{[173,174]}$. Carbon tetrachloride treatment enhances both fibrosis and LGR5+ liver stem cell growth, whereas LGR5 downregulation aggravates fibrosis. HGF together with Rspo1 increases the number of LGR5+ liver stem cells and enhances hepatic function by inhibiting fibrosis ${ }^{[175]}$. Both Carbon tetrachloride-induced acute damage and oval cell response to damage can induce LGR5+ stem cells/ progenitors actively engaged in hepatic reconstitution via de novo generation of hepatocytes ${ }^{[15]}$. Effendi et al. ${ }^{[176]}$ addressed that LGR5 upregulated HCC cells showed more potent colony-forming capability and possessed higher therapeutic resistant to a cytotoxic drug and weakened migration ability than the controls. Further, LGR5 overexpressed HCC cells produces nodule-type metastases in the livers of immunodeficient mice, whereas vector-transfected HCC cells generates more invasive tumors ${ }^{[176]}$. Lei et al ${ }^{[177]}$ unraveled that the LSD1/ Prickle1/APC/ $\beta$-catenin signaling axis is engaged in regulating the stem characteristics and chemoresistance of hepatic LGR5+ LCSCs.

\section{TREATMENT TARGETING LCSCs}

Using surface markers to identify and isolate LCSCs remains an initial and important step of CSC-targeting therapy. Immunotherapy uses specific antibodies to target LCSC surface makers can be integrated with conventional chemotherapy, radiotherapy and surgery to promote therapeutic effects. The most frequentlyused LCSC-associated surface markers along with clinical strategies that target them are demonstrated as follows.

One of the current therapeutic approaches to target directly LCSCs is nanomedicine-based therapy, in which medication delivery and intake are effectively controlled in nanoscale ${ }^{[178]}$. Epirubicin-adsorbed nanodiamonds displayed high efficacy in inducing the elimination of chemoresistant LCSCs ${ }^{[179]}$. Poly lacticco-glycolic acid-encapsulated disulfiram strongly inhibits LCSCs and has a synergistic cytotoxicity with 5-FU or sorafenib ${ }^{[180]}$. Gao et al..$^{[181]}$ developed a GPC3-targeted CAR and found that it obviously suppressesed HCC growth. Overexpression of ANXA3 increased the number of CD133+ cells and positively associated with tumorigenicity of CD133+ cells. The underlying mechanism of ANXA3-mediated maintenance of LCSCs stemness involved the HIF1A/Notch pathway. ANXA3 upregulated dendritic cells could induce more active $\mathrm{T}$ cells , which could preferentially kill CD133+ $\mathrm{LCSCs}^{[182]}$. Xu et al. ${ }^{[183]}$ addressed that Hep-12 cells owing stemness properties, are susceptible to autologous-activated tumor-infiltrating lymphocytesmediated recognition and cytotoxicity. What's more remarkable, the authors put forward that it may be the first evidence to demonstrate the hypothesis that immunotherapy can be used to target recurrent HCC cells with stem cell-like properties. Bone morphogenetic protein-9 is a potent growth inhibitor of hepatocellular carcinoma and reduces the liver cancer stem cells population by suppressing the expression of five prominent LCSC markers, including CD44, CD90, AFP, GPC3 and ANPEP ${ }^{[184]}$. In current clinical practice (according to 
NCCN guidelines for hepatobiliary cancers, version 4.2018), several oral targeted drugs have been approved, including sorafenib, lenvatinib, regorafenib, showed a median overall survival of 10.7 to 13.6 months ${ }^{[185-187]}$. Immunotherapy has also been considered as one of the promising treatments and is being actively studied and optimized in liver cancer progression and metastasis ${ }^{[188]}$. The most ex vivo investigated and clinically relevant check-point proteins are CTLA-4, PD-1, and PD-L1. Nivolumab and pembrolizumb, both as PD-1 antibodies with similar efficacy, are now approved to treat liver cancer clinically. Nivolumab showed an objective response of $20 \%$, contained $1 \%$ complete response and $18 \%$ partial response, and stable disease is $45 \%{ }^{[189]}$, when pembrolizumb is concerned, the objective response is $17 \%$, and the complete responses, partial response, and stable disease were $1 \%, 16 \%$ and $44 \%$ respectively ${ }^{[190]}$. The development of new drugs enable the improvement of object responses and survival of advanced liver cancer, what's deserved notification is that drugs such as sorafenib, lenvatinib, regorafenib, nivolumab and pembrolizumb now available in clinic can obtained about $1 \%$ clinical complete response in small number of patients, revealing the pathways these drugs targeted may have the potential to diminished almost the whole tumor including the LCSC, and further exploration of the underlying mechanism of cancer development and progression is promising.

Alternative therapies including induction of LCSC differentiation and apoptosis are also promising. Conventional chemotherapy and radiotherapy have been proven to successfully eradicate terminally differentiated cancer cells but fail to influence CSCs ${ }^{[191,192]}$. Therapies that induce LCSC differentiation can be combined with those conventional therapies to efficiently diminish LCSC subpopulation and impede cancer development since the differentiation process obtains higher priority than cancer self-renewal process. There are intensive studies developing and optimizing the differentiation-inducing agents including retinoic acid, histone deacetylase inhibitors, tyrosine-kinase, Hippo/YAP signaling pathway inhibitors ${ }^{[192-195]}$. Apoptosis is also a vital cellular mechanism that regulates cell death through a complicated signaling network. LCSCs can escape from apoptosis process, therefore they possess unlimited and uncontrollable self-renewal ability to initiate cancer development and invasion. Induction of apoptotic mechanism in LCSCs by using microRNA hold great promise in cancer treatment so that many studies have been focused on developing therapies to activate apoptotic pathways in LCSCs ${ }^{[196]}$.

These inducing therapies would be feasible and efficient if LCSCs could be specifically identified according to the expression profile of varied LCSC surface markers. However, there is no LCSC surface marker has been identified and proven to have the ability to represent the entire subpopulation of LCSCs, thereby the inducing therapies remain challenging so far. It leads us to consider that whether or not the potential combination of varied LCSC surface markers can improve the specificity in identification of LCSCs.

\section{SUMMARY}

The above-mentioned discussion offers a promising insight of how LCSCs can be employed in clinical diagnosis and treatment for liver cancer development, progression, metastasis and resistance [Figure 2]. During the last decades, the compelling knowledge about CSCs has enabled rapid advances of drugs targeting CSCs and gradually emerged as an indispensable class of therapies. Numerous agents with the capabilities to inhibit CSC-associated signaling pathways, including Notch pathway, Hedgehog pathway and WNT pathway, have been approved for clinical use. The recent development of culture condition allows CSCs to undergo long-term proliferation in spheroids and organoids, thus offer researchers with an innovative platform for identifying new CSC markers with high specificity and efficacy. Moreover, because organoids are directly derived from primary tumor tissues, the organoid technique provides a unique perspective to researchers so that we can comprehensively investigate the heterogeneous functions of CSCs in recurrence, metastasis, chemoresistance and radioresistance.

From a broader perspective, there is no doubt that drugs targeting CSC should be considered as a promising clinical strategy for therapeutic intervention, although the rate of treatment failure that aims to effectively 


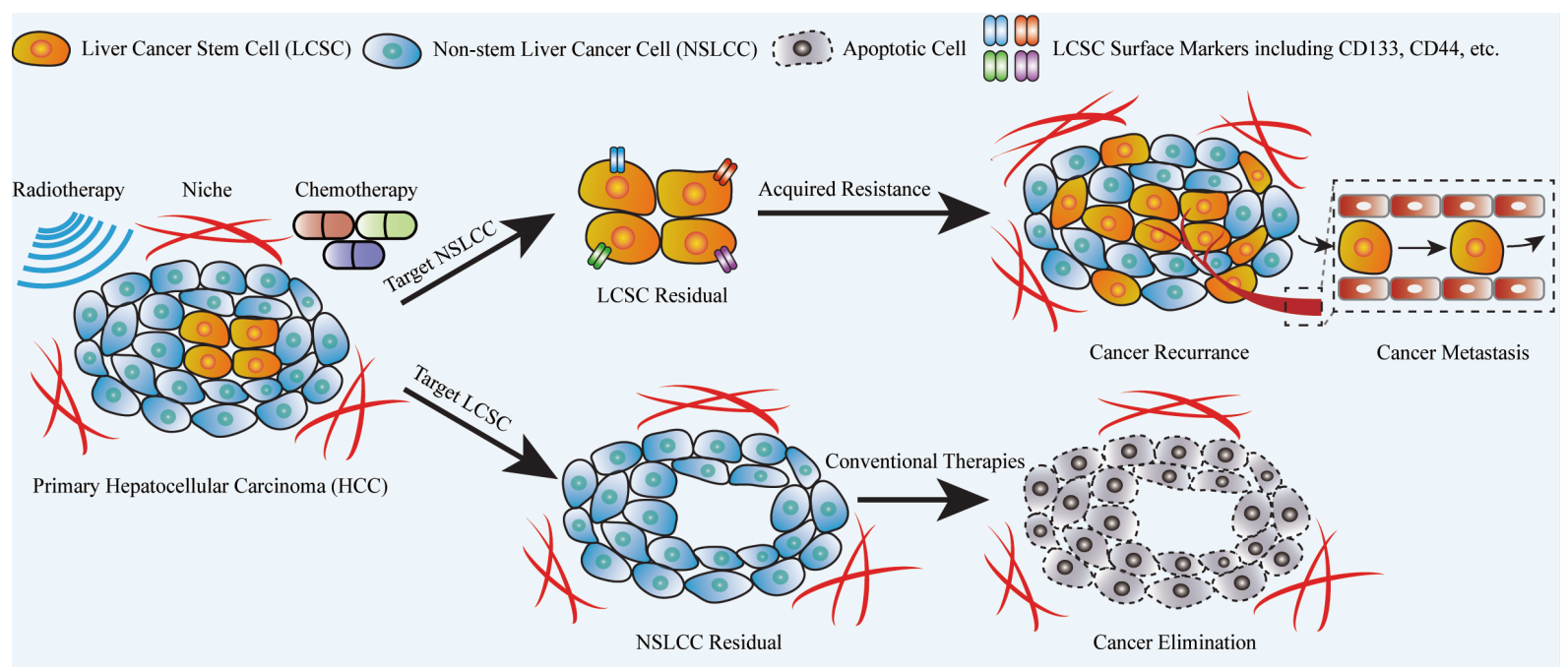

Figure 2. Clinical implication of conventional cancer therapy and LCSC-targeting therapy. Conventional chemotherapy and radiotherapy are frequently used to treat liver cancer, effectively targeting the non-stem liver cancer cells (NSLCCS) but not liver cancer stem cells (LCSCs). The LCSC residual can be re-activated to enrich the LCSC subpopulation and eventually trigger cancer recurrence and metastasis with a more aggressive phenotype. With the help of varied LCSC surface markers that can specifically and effectively identify LCSC heterogeneity, LCSC-targeting therapy is believed to be capable of eradicating the CSC subpopulation in liver cancer. Integration of LCSC-targeting therapy and conventional chemo-/radiotherapy might lead to complete cancer elimination without further development and invasion. LCSC-targeting therapy has generated many promising results in pre-clinical trials and there are intensive efforts from researchers and clinicians for further research.

eliminate CSCs remains relatively high so far. It is worth considering that such treatment failure might be resulted from inefficiency of drug delivery instead of inefficiency of the drugs. Promoting the efficacy of drug delivery and developing alternative approaches to target CSCs represent one of the most foremost fields to be explored. In addition, early diagnosis of cancer by using CSC markers remains as an important ramification that can prevent development, metastasis and resistance. Hence, there is an emergency for greater concentration on identification of CSC markers that can specifically and effectively represent tumor grades and disease stages. Integrating the development of early diagnosis techniques with a comprehensive understanding of CSC surface markers that drive a benign stage to a malignant stage can enable patientspecific and efficient early intervention and offer a balanced approach to regulating cancer development and invasion.

\section{DECLARATIONS}

\section{Authors' contributions}

Designed the structure and outline of the manuscript, instructed writing the intellectual part, and approved final publication: Guan XY

Reviewed the literatures and wrote the draft: Zhang JL

Revised the manuscript and drew the pictures: Gong LQ

Review and minorly revised the manuscript: Yan Q, Zhou NN, Lee VHF

\section{Availability of data and materials}

Not applicable.

\section{Financial support and sponsorship}

This study was supported by a grant of the Basic Research (Discipline Layout) of Shenzhen Science and Technology Project (No. JCYJ20180508153249223). 


\section{Conflicts of interest}

All authors declared that there are no conflicts of interest.

\section{Ethical approval and consent to participate}

Not applicable.

\section{Consent for publication}

Not applicable.

\section{Copyright}

(c) The Author(s) 2019.

\section{REFERENCES}

1 Bray F, Ferlay J, Soerjomataram I, Siegel RL, Torre LA, et al. Global cancer statistics 2018: GLOBOCAN estimates of incidence and mortality worldwide for 36 cancers in 185 countries. CA cancer J Clin 2018;68:394-424.

2 Ma S, Chan KW, Hu L, Lee TK, Wo JY, et al. Identification and characterization of tumorigenic liver cancer stem/progenitor cells. Gastroenterology 2007;132:2542-56.

3 Mima K, Okabe H, Ishimoto T, Hayashi H, Nakagawa S, Kuroki H, et al. CD44s regulates the TGF- $\beta$-mediated mesenchymal phenotype and is associated with poor prognosis in patients with hepatocellular carcinoma. Cancer Res 2012;72:3414-23.

4 Yang ZF, Ho DW, Ng MN, Lau CK, Yu WC, et al. Significance of CD90+ cancer stem cells in human liver cancer. Cancer Cell 2008;13:153-66.

5 Yamashita T, Ji J, Budhu A, Forgues M, Yang W, et al. EpCAM-positive hepatocellular carcinoma cells are tumor-initiating cells with stem/progenitor cell features. Gastroenterology 2009;136:1012-24.

6 Lee TK, Cheung VC, Lu P, Lau EY, Ma S, et al. Blockade of CD47-mediated cathepsin S/protease-activated receptor 2 signaling provides a therapeutic target for hepatocellular carcinoma. Hepatology 2014;60:179-91.

7 Park SC, Zeng C, Tschudy-Seney B, Nguyen NT, Eun JR, et al. Clonogenically Culturing and Expanding CD34+ Liver Cancer Stem Cells in Vitro. Stem Cells Dev 2015;24:1506-14.

8 Mansuroglu T, Baumhoer D, Dudas J, Haller F, Cameron S, et al. Expression of stem cell factor receptor c-kit in human nontumoral and tumoral hepatic cells. Eur J Gastroenterol Hepatol 2009;21:1206-11.

9 Haraguchi N, Ishii H, Mimori K, Tanaka F, Ohkuma M, et al. CD13 is a therapeutic target in human liver cancer stem cells. J Clin Invest 2010;120:3326-39.

10 Lee TK, Castilho A, Cheung VC, Tang KH, Ma S, et al. CD24(+) Liver Tumor-Initiating Cells Drive Self-Renewal and Tumor Initiation through STAT3-Mediated NANOG Regulation. Cell Stem Cell 2011;9:50-63.

11 Zhao W, Wang L, Han H, Jin K, Lin N, et al. 1B50-1, a mAb raised against recurrent tumor cells, targets liver tumor-initiating cells by binding to the calcium channel $\alpha 2 \delta 1$ subunit. Cancer Cell 2013;23:541-56.

12 Yang W, Wang C, Lin Y, Liu Q, Yu LX, et al. $\mathrm{OV6}^{+}$tumor-initiating cells contribute to tumor progression and invasion in human hepatocellular carcinoma. J Hepatol 2012;57:613-20.

13 Li H, Cui ML, Chen TY, Xie HY, Cui Y, et al. Serum DLK1 is a potential prognostic biomarker in patients with hepatocellular carcinoma. Tumour Biol 2015;36:8399-404.

14 Kawai T, Yasuchika K, Ishii T, Katayama H, Yoshitoshi EY, et al. Keratin 19, a Cancer Stem Cell Marker in Human Hepatocellular Carcinoma. Clin Cancer Res 2015;21:3081-91.

15 Huch M, Dorrell C, Boj SF, van Es JH, Li VS, et al. In vitro expansion of single Lgr5+ liver stem cells induced by Wnt-driven regeneration. Nature 2013;494:247-50.

16 Yin AH, Miraglia S, Zanjani ED, Almeida-Porada G, Ogawa M, et al. AC133, a novel marker for human hematopoietic stem and progenitor cells. Blood 1997;90:5002-12.

17 Corbeil D, Röper K, Hellwig A, Tavian M, Miraglia S, et al. The human AC133 hematopoietic stem cell antigen is also expressed in epithelial cells and targeted to plasma membrane protrusions. J Biol Chem 2000;275:5512-20.

18 Miraglia S, Godfrey W, Yin AH, Atkins K, Warnke R, et al. A novel five-transmembrane hematopoietic stem cell antigen: isolation, characterization, and molecular cloning. Blood 1997;90:5013-21.

19 Grosse-Gehling P, Fargeas CA, Dittfeld C, Garbe Y, Alison MR, et al. CD133 as a biomarker for putative cancer stem cells in solid tumours: limitations, problems and challenges. J Pathol 2013;229:355-78.

20 Singh SK, Clarke ID, Terasaki M, Bonn VE, Hawkins C, et al. Identification of a cancer stem cell in human brain tumors.Cancer Res 2003;63:5821-8.

21 Wang S, Xu ZY, Wang LF, Su W. CD133+ cancer stem cells in lung cancer. Front Biosci (Landmark Ed) 2013;18:447-53.

22 Chen S, Hou JH, Feng XY, Zhang XS, Zhou ZW, et al. Clinicopathologic significance of putative stem cell marker, CD44 and CD133, in human gastric carcinoma. J Surg Oncol 2013;107:799-806.

23 Hori Y. Prominin-1 (CD133) reveals new faces of pancreatic progenitor cells and cancer stem cells: current knowledge and therapeutic 
perspectives. Adv Exp Med Biol 2013;777:185-96.

24 Chiba T, Kita K, Zheng YW, Yokosuka O, Saisho H, et al. Side population purified from hepatocellular carcinoma cells harbors cancer stem cell-like properties. Hepatology 2010;44:240-51.

25 Ma S, Chan KW, Lee TK, Tang KH, Wo JY, et al. Aldehyde dehydrogenase discriminates the CD133 liver cancer stem cell populations. Mol Cancer Res 2008;6:1146-53.

26 Lan X, Wu YZ, Wang Y, Wu FR, Zang CB, et al. CD133 silencing inhibits stemness properties and enhances chemoradiosensitivity in CD133-positive liver cancer stem cells. Int J Mol Med 2013;31:315-24.

27 Piao LS, Hur W, Kim TK, Hong SW, Kim SW, et al. CD133 + liver cancer stem cells modulate radioresistance in human hepatocellular carcinoma. Cancer Lett 2012;315:129-37.

28 Suetsugu A, Nagaki M, Aoki H, Motohashi T, Kunisada T, et al. Characterization of CD133+ hepatocellular carcinoma cells as cancer stem/progenitor cells. Biochem Biophys Res Commun 2006;351:820-4.

29 Ma S, Tang KH, Chan YP, Lee TK, Kwan PS, et al. miR-130b Promotes CD133 Liver Tumor-Initiating Cell Growth and Self-Renewal via Tumor Protein 53-Induced Nuclear Protein 1. Cell Stem Cell 2010;7:694-707.

30 Ma S, Lee TK, Zheng BJ, Chan KW, Guan XY. CD133+ HCC cancer stem cells confer chemoresistance by preferential expression of the Akt/PKB survival pathway. Oncogene 2008;27:1749-58.

31 Tong CM, Ma S, Guan XY. Biology of hepatic cancer stem cells. J Gastroenterol Hepatol 2011;26:1229-37.

32 Liu YM, Li XF, Liu H, Wu XL. Ultrasound-targeted microbubble destruction-mediated downregulation of CD133 inhibits epithelialmesenchymal transition, stemness and migratory ability of liver cancer stem cells. Oncol Rep 2015;34:2977-86.

33 Tang KH, Ma S, Lee TK, Chan YP, Kwan PS, et al. CD133(+) liver tumor-initiating cells promote tumor angiogenesis, growth, and selfrenewal through neurotensin/interleukin-8/CXCL1 signaling. Hepatology 2012;55:807-20.

34 Li J, Chen JN, Zeng TT, He F, Chen SP, et al. CD133+ liver cancer stem cells resist interferon-gamma-induced autophagy. BMC Cancer 2016;16:15.

35 Chen H, Luo Z, Sun W, Zhang C, Sun H, et al. Low glucose promotes CD133mAb-elicited cell death via inhibition of autophagy in hepatocarcinoma cells. Cancer Lett 2013;336:204-12.

36 Piao LS, Hur W, Kim TK, Hong SW, Kim SW, et al. CD133+ liver cancer stem cells modulate radioresistance in human hepatocellular carcinoma. Cancer Lett 2012;315:129-37.

37 Rountree CB, Ding W, He L, Stiles B. Expansion of CD133-expressing liver cancer stem cells in liver-specific phosphatase and tensin homolog deleted on chromosome 10-deleted mice. Stem Cells 2009;27:290-9.

38 Jang JW, Song Y, Kim SH, Kim JS, Kim KM, et al. CD133 confers cancer stem-like cell properties by stabilizing EGFR-AKT signaling in hepatocellular carcinoma. Cancer Lett 2017;389:1-10.

39 Hagiwara S, Kudo M, Nagai T, Inoue T, Ueshima K, et al. Activation of JNK and high expression level of CD133 predict a poor response to sorafenib in hepatocellular carcinoma. Br J Cancer 2012;106:1997-2003.

40 Yang Z, Zhang L, Ma A, Liu L, Li J, et al. Transient mTOR inhibition facilitates continuous growth of liver tumors by modulating the maintenance of CD133+ cell populations. PLoS One 2011;6:e28405.

41 You H, Ding W, Rountree CB. Epigenetic regulation of cancer stem cell marker CD133 by transforming growth factor-beta. Hepatology 2010;51:1635-44.

42 Chen CL, Tsukamoto H, Liu JC, Kashiwabara C, Feldman D, et al. Reciprocal regulation by TLR4 and TGF- $\beta$ in tumor-initiating stemlike cells. J Clin Invest 2013;123:2832-49.

43 Ezzeldin M, Borrego-Diaz E, Taha M, Esfandyari T, Wise AL, et al. RalA signaling pathway as a therapeutic target in hepatocellular carcinoma (HCC). Mol Oncol 2014;8:1043-53.

44 Wang R, Li Y, Tsung A, Huang H, Du Q, et al. iNOS promotes CD24+ CD133+ liver cancer stem cell phenotype through a TACE/ ADAM17-dependent Notch signaling pathway. Proc Natl Acad Sci U S A 2018;115:E10127-E36.

45 Tang Y, Berlind J, Mavila N. Inhibition of CREB binding protein-beta-catenin signaling down regulates CD133 expression and activates PP2A-PTEN signaling in tumor initiating liver cancer cells. Cell Commun Signal 2018;16:9.

46 Luk STC, Tong M, Ng KY, Yip KY-L, Guan XY, Ma S. Identification of ZFP42/REX1 as a regulator of cancer stemness in CD133+ liver cancer stem cells by genome-wide DNA methylation analysis. AACR Annual Meeting 2018;DOI: 10.1158/1538-7445.

47 Pardoll DM. The blockade of immune checkpoints in cancer immunotherapy. 2012;12(4):252.

48 Chai S, Tong M, Ng KY, Kwan PS, Chan YP, et al. Regulatory role of miR-142-3p on the functional hepatic cancer stem cell marker CD133. Oncotarget 2014;5:5725-35.

49 Huang H, Hu M, Li P, Lu C, Li M. Mir-152 inhibits cell proliferation and colony formation of CD133(+) liver cancer stem cells by targeting KIT. Tumour Biol 2015;36:921-8.

50 Chai S, Ng KY, Tong M, Lau EY, Lee TK, et al. Octamer 4/microRNA-1246 signaling axis drives Wnt/ $\beta$-catenin activation in liver cancer stem cells. Hepatology 2016;64:2062-76.

51 Wilson GS, Hu Z, Duan W, Tian A, Wang XM, et al. Efficacy of using cancer stem cell markers in isolating and characterizing liver cancer stem cells. Stem Cells Dev 2013;22:2655-64.

52 Chen Y, Yu D, Zhang H, He H, Zhang C, et al. CD133(+)EpCAM(+) phenotype possesses more characteristics of tumor initiating cells in hepatocellular carcinoma Huh7 cells. Int J Biol Sci 2012;8:992-1004.

53 Song W, Li H, Tao K, Li R, Song Z, et al. Expression and clinical significance of the stem cell marker CD133 in hepatocellular carcinoma. Int J Clin Pract 2008;62:1212-8.

54 Sasaki A, Kamiyama T, Yokoo H, Nakanishi K, Kubota K, et al. Cytoplasmic expression of CD133 is an important risk factor for overall 
survival in hepatocellular carcinoma. Oncol Rep 2010;24:537-46.

55 Lin CY, Chen TC, Lai MW, Chia-Jung K, Chau-Ting Y, et al. CD133-positive hepatocellular carcinoma in an area endemic for hepatitis B virus infection. BMC Cancer 2009;9:1-11.

56 Ma YC, Yang JY, Yan LN. Relevant markers of cancer stem cells indicate a poor prognosis in hepatocellular carcinoma patients: a metaanalysis. Eur J Gastroenterol Hepatol 2013;25:1007-16.

57 Huang L, Bian S, Cheng Y, Shi G, Liu P, et al. Microfluidics cell sample preparation for analysis:advances in efficient cell enrichment and precise single cell capture. Biomicrofluidics 2017;11:011501.

58 Chen ZZ, Huang L, Wu YH, Zhai WJ, Zhu PP, et al. LncSox4 promotes the self-renewal of liver tumour-initiating cells through Stat3mediated Sox4 expression. Nat Commun 2016;7:12598.

59 Smith LM, Nesterova A, Ryan MC, Duniho S, Jonas M, et al. CD133/prominin-1 is a potential therapeutic target for antibody-drug conjugates in hepatocellular and gastric cancers. Br J Cancer 2008;99:100-9.

60 Lang J, Lan X, Liu Y, Jin X, Wu T, et al. Targeting cancer stem cells with an (131)I-labeled anti-AC133 monoclonal antibody in human colorectal cancer xenografts. Nucl Med Biol 2015;42:505-12.

61 Huang J, Li C, Wang Y, Lv H, Guo Y, et al. Cytokine-induced killer (CIK) cells bound with anti-CD3/anti-CD133 bispecific antibodies target CD133high cancer stem cells in vitro and in vivo. Clin Immunol 2013;149:156-68.

62 Gallatin WM, Weissman IL, Butcher EC. A cell-surface molecule involved in organ-specific homing of lymphocytes. Nature 1983;304:30-4.

63 Haegel H, Dierich A, Ceredig R. CD44 in differentiated embryonic stem cells: surface expression and transcripts encoding multiple variants. Dev Immunol 1994;3:239-46.

64 Bruns I, Cadeddu RP, Brueckmann I, Fröbel J, Geyh S, et al. Multiple myeloma-related deregulation of bone marrow-derived CD34+ hematopoietic stem and progenitor cells. Blood 2012;120:2620-30.

65 Campagnoli C, Roberts IA, Kumar S, Bennett PR, Bellantuono I, et al. Identification of mesenchymal stem/progenitor cells in human first-trimester fetal blood, liver, and bone marrow. Blood 2001;98:2396-402.

66 Du L, Wang H, He L, Zhang J, Ni B, et al. CD44 is of functional importance for colorectal cancer stem cells. Clin Cancer Res 2008;14:6751-60.

67 Chenwei L, Heidt DG, Piero D, Burant CF, Lanjing Z, Volkan A, Max W, Clarke MF, Simeone DM, \%J Journal of Surgical Research. Identification of pancreatic cancer stem cells. 2006; 130: 194-195

68 Prince ME, Sivanandan R, Kaczorowski A, Wolf GT, Kaplan MJ, et al. Identification of a subpopulation of cells with cancer stem cell properties in head and neck squamous cell carcinoma. Proc Natl Acad Sci U S A 2007;104:973-8.

69 Al-Hajj M, Wicha MS, Benito-Hernandez A, Morrison SJ, Clarke MF. Prospective identification of tumorigenic breast cancer cells. 2003;100(7):3983-8.

70 Goldstein LA, Zhou DF, Picker LJ, Minty CN, Bargatze RF, et al. A human lymphocyte homing receptor, the hermes antigen, is related to cartilage proteoglycan core and link proteins. Cell 1989;56:1063-72.

71 Screaton GR, Bell MV, Bell JI, Jackson DG. The identification of a new alternative exon with highly restricted tissue expression in transcripts encoding the mouse Pgp-1 (CD44) homing receptor. Comparison of all 10 variable exons between mouse, human, and rat. J Biol Chem 1993;268:12235-8.

72 Screaton GR, Bell MV, Jackson DG, Cornelis FB, Gerth U, et al. Genomic structure of DNA encoding the lymphocyte homing receptor CD44 reveals at least 12 alternatively spliced exons. Proc Natl Acad Sci U S A 1992;89:12160-4.

73 Harn HJ, Ho LI, Yu CP, Wang MW, Lee HS, et al. The variant mRNA isoform of human metastasis gene (CD44V) detected in the cell lines of human hepatocellular carcinoma. Biochem Mol Biol Int 1994;32:233-8.

74 van Weering DH, Baas PD, Bos JL. A PCR-based method for the analysis of human CD44 splice products. PCR Methods Appl 1993;3:100-6.

75 Williams K, Motiani K, Giridhar PV, Kasper S. CD44 integrates signaling in normal stem cell, cancer stem cell and (pre)metastatic niches. Exp Biol Med (Maywood) 2013;238:324-38.

76 Kon J, Ooe H, Oshima H, Kikkawa Y, Mitaka T. Expression of CD44 in rat hepatic progenitor cells. J Hepatol 2006;45:90-8.

77 Mima K, Okabe H, Ishimoto T, Hayashi H, Nakagawa S, et al. CD44s regulates the TGF- $\beta$-mediated mesenchymal phenotype and is associated with poor prognosis in patients with hepatocellular carcinoma. Cancer Res 2012;72:3414-23.

78 Wan S, Zhao E, Kryczek I, Vatan L, Sadovskaya A, et al. Tumor-associated macrophages produce interleukin 6 and signal via STAT3 to promote expansion of human hepatocellular carcinoma stem cells. Gastroenterology 2014;147:1393-404.

79 Zhu Z, Hao X, Yan M, Yao M, Ge C, et al. Cancer stem/progenitor cells are highly enriched in CD133+CD44+ population in hepatocellular carcinoma. Int J Cancer 2010;126:2067-78.

80 Zhang T, Gong T, Xie J, Lin S, Liu Y, et al. Softening substrates promote chondrocytes phenotype via RhoA/ROCK pathway. ACS Appl Mater Interfaces 2016;8:22884-91.

81 Dhar D, Antonucci L, Nakagawa H, Kim JY, Glitzner E, et al. Liver cancer initiation requires p53 inhibition by CD44-enhanced growth factor signaling. Cancer Cell 2018;33:1061-77.

82 Fan Z, Xia H, Xu H, Ma J, Zhou S, et al. Standard CD44 modulates YAP1 through a positive feedback loop in hepatocellular carcinoma. Biomed Pharmacother 2018;103:147-56.

83 Kopanja D, Pandey A, Kiefer M, Wang Z, Chandan N, et al. Essential roles of FoxM1 in Ras-induced liver cancer progression and in cancer cells with stem cell features. J Hepatol 2015;63:429-36.

84 Zheng X, Zhang F, Zhao Y, Zhang J, Dawulieti J, et al. Self-assembled dual fluorescence nanoparticles for CD44-targeted delivery of 
anti-miR-27a in liver cancer theranostics. Theranostics 2018;8:3808-23.

85 Rani B, Malfettone A, Dituri F, Soukupova J, Lupo L, et al. Galunisertib suppresses the staminal phenotype in hepatocellular carcinoma by modulating CD44 expression. Cell Death Dis 2018;9:373.

86 Badawi M, Kim J, Dauki A, Sutaria D, Motiwala T, et al. CD44 positive and sorafenib insensitive hepatocellular carcinomas respond to the ATP-competitive mTOR inhibitor INK128. Oncotarget 2018;9:26032-45.

87 Reif AE, Allen JM. THE AKR THYMIC ANTIGEN AND ITS DISTRIBUTION IN LEUKEMIAS AND NERVOUS TISSUES. J Exp Med 1964;120:413-33.

88 Schlesinger M, Yron I. Antigenic changes in lymph-node cells after administration of antiserum to thymus cells. Science 1969;164:1412-3.

89 Ades EW, Zwerner RK, Acton RT, Balch CM. Isolation and partial characterization of the human homologue of Thy-1. J Exp Med 1980;151:400-6.

90 Rege TA, Hagood JS. Thy-1 as a regulator of cell-cell and cell-matrix interactions in axon regeneration, apoptosis, adhesion, migration, cancer, and fibrosis. FASEB J 2006;20:1045-54.

91 Zhang K, Che S, Pan C, Su Z, Zheng S, et al. The SHH/Gli axis regulates CD90-mediated liver cancer stem cell function by activating the IL6/JAK2 pathway. J Cell Mol Med 2018;22:3679-90.

92 Nomura Y, Yamashita T, Oishi N, Nio K, Hayashi T, et al. De novo emergence of mesenchymal stem-like CD105 + cancer cells by cytotoxic agents in human hepatocellular carcinoma. Transl Oncol 2017;10:184-9.

93 Jia Q, Zhang X, Deng T, Gao J. Positive correlation of Oct4 and ABCG2 to chemotherapeutic resistance in CD90(+)CD133(+) liver cancer stem cells. Cell Reprogram 2013;15:143-50.

94 Zhu L, Zhang W, Wang J, Liu R. Evidence of CD90+CXCR4+ cells as circulating tumor stem cells in hepatocellular carcinoma. Tumour Biol 2015;36:5353-60.

95 Yamashita T, Honda M, Nakamoto Y, Baba M, Nio K, et al. Discrete nature of EpCAM+ and CD90+ cancer stem cells in human hepatocellular carcinoma. Hepatology 2013;57:1484-97.

96 Wang Y, Wang B, Xiao S, Li Y, Chen Q. miR-125a/b inhibits tumor-associated macrophages mediated in cancer stem cells of hepatocellular carcinoma by targeting CD90. J Cell Biochem 2019;120:3046-55.

97 Zhang K, Che S, Su Z, Zheng S, Zhang H, et al. CD90 promotes cell migration, viability and sphere-forming ability of hepatocellular carcinoma cells. Int J Mol Med 2018;41:946-54.

98 Lu JW, Chang JG, Yeh KT, Chen RM, Tsai JJ, et al. Overexpression of Thy1/CD90 in human hepatocellular carcinoma is associated with HBV infection and poor prognosis. Acta Histochem 2011;113:833-8.

99 Herlyn M, Steplewski Z, Herlyn D, Koprowski H. Colorectal carcinoma-specific antigen: detection by means of monoclonal antibodies. Proc Natl Acad Sci U S A 1979;76:1438-42.

100 Sears HF, Atkinson B, Mattis J, Ernst C, Herlyn D, et al. Phase-I clinical trial of monoclonal antibody in treatment of gastrointestinal tumours. Lancet 1982;1:762-5.

101 Sears HF, Herlyn D, Steplewski Z, Koprowski H. Effects of monoclonal antibody immunotherapy on patients with gastrointestinal adenocarcinoma. J Biol Response Mod 1984;3:138-50.

102 Baeuerle P, Gires O. EpCAM (CD326) finding its role in cancer. Br J Cancer 2007;96:417-23.

103 Schmelzer E, Reid LM. EpCAM expression in normal, non-pathological tissues. Front Biosci 2008;13:3096-100.

104 Yamashita T, Budhu A, Forgues M, Wang XW. Activation of hepatic stem cell marker EpCAM by Wnt-beta-catenin signaling in hepatocellular carcinoma. Cancer Res 2007;67:10831-9.

105 Nio K, Yamashita T, Okada H, Kondo M, Hayashi T, et al. Defeating EpCAM + liver cancer stem cells by targeting chromatin remodeling enzyme CHD4 in human hepatocellular carcinoma. J Hepatol 2015;63:1164-72.

106 Yamashita T, Honda M, Nio K, Nakamoto Y, Yamashita T, et al. Oncostatin m renders epithelial cell adhesion molecule-positive liver cancer stem cells sensitive to 5-Fluorouracil by inducing hepatocytic differentiation. Cancer Res 2010;70:4687-97.

107 Zhang Y, Guan DX, Shi J, Gao H, Li JJ, et al. All-trans retinoic acid potentiates the chemotherapeutic effect of cisplatin by inducing differentiation of tumor initiating cells in liver cancer. J Hepatol 2013;59:1255-63.

108 Chiba T, Suzuki E, Negishi M, Saraya A, Miyagi S, et al. 3-Deazaneplanocin A is a promising therapeutic agent for the eradication of tumor-initiating hepatocellular carcinoma cells. Int J Cancer 2012;130:2557-67.

109 Ji J, Zheng X, Forgues M, Yamashita T, Wauthier EL, et al. Identification of microRNAs specific for epithelial cell adhesion moleculepositive tumor cells in hepatocellular carcinoma. Hepatology 2015;62:829-40.

110 Xia H, Ooi LL, Hui KM. MicroRNA-216a/217-induced epithelial-mesenchymal transition targets PTEN and SMAD7 to promote drug resistance and recurrence of liver cancer. Hepatology 2013;58:629-41.

111 Ji J, Yamashita T, Budhu A, Forgues M, Jia HL, et al. Identification of microRNA-181 by genome-wide screening as a critical player in EpCAM-positive hepatic cancer stem cells. Hepatology 2009;50:472-80.

112 Yamashita T, Forgues M, Wang W, Kim JW, Ye Q, et al. EpCAM and alpha-fetoprotein expression defines novel prognostic subtypes of hepatocellular carcinoma. Cancer Res 2008;68:1451-61.

113 Chen J, Liu Q, Xiao J, Du J. EpCAM-antibody-labeled noncytotoxic polymer vesicles for cancer stem cells-targeted delivery of anticancer drug and siRNA. Biomacromolecules 2015;16:1695-705.

114 Saito T, Chiba T, Yuki K, Zen Y, Oshima M, et al. Metformin, a diabetes drug, eliminates tumor-initiating hepatocellular carcinoma cells. PLoS One 2013;8:e70010.

115 Babaei M, Abnous K, Taghdisi SM, Amel Farzad S, Peivandi MT, et al. Synthesis of theranostic epithelial cell adhesion molecule targeted mesoporous silica nanoparticle with gold gatekeeper for hepatocellular carcinoma. Nanomedicine (Lond) 2017;12:1261-79. 
116 Kurtz JE, Dufour P. Adecatumumab: an anti-EpCAM monoclonal antibody, from the bench to the bedside. Expert Opin Biol Ther 2010;10:951-8.

117 Campbell IG, Freemont PS, Foulkes W, Trowsdale J. An ovarian tumor marker with homology to vaccinia virus contains an IgV-like region and multiple transmembrane domains. Cancer Res 1992;52:5416-20

118 Willingham SB, Volkmer JP, Gentles AJ, Sahoo D, Dalerba P, et al. The CD47-signal regulatory protein alpha (SIRPa) interaction is a therapeutic target for human solid tumors. Proc Natl Acad Sci U S A 2012;109:6662-7.

119 Brown EJ, Frazier WA. Integrin-associated protein (CD47) and its ligands. Trends Cell Biol 2001;11:130-5.

120 Chi HC, Lee KW, Ng OL. Abstract 2453: CD47 is a novel therapeutic target for hepatocellular carcinoma. Tumor Biology 2011;71:2453.

121 Chao MP, Weissman IL, Majeti R. The CD47-SIRP $\alpha$ pathway in cancer immune evasion and potential therapeutic implications. Curr Opin Immunol 2012;24:225-32.

122 Lo J, Lau EY, Ching RH, Cheng BY, Ma MK, et al. Nuclear factor kappa B-mediated CD47 up-regulation promotes sorafenib resistance and its blockade synergizes the effect of sorafenib in hepatocellular carcinoma in mice. Hepatology 2015;62:534-45.

123 Casey SC, Tong L, Li Y, Do R, Walz S, et al. MYC regulates the antitumor immune response through CD47 and PD-L1. Science 2016;352:227-31.

124 Rodríguez MM, Fiore E, Bayo J, Atorrasagasti C, García M, et al. 4Mu Decreases CD47 Expression on Hepatic Cancer Stem Cells and Primes a Potent Antitumor T Cell Response Induced by Interleukin-12. Mol Ther 2018;26:2738-50.

125 Jiang P, Lagenaur CF, Narayanan V. Integrin-associated protein is a ligand for the P84 neural adhesion molecule. J Biol Chem 1999;274:559-62.

126 Xiao Z, Chung H, Banan B, Manning PT, Ott KC, et al. Antibody mediated therapy targeting CD47 inhibits tumor progression of hepatocellular carcinoma. Cancer Lett 2015;360:302-9.

127 Zhao XW, van Beek EM, Schornagel K, Van der Maaden H, Van Houdt M, et al. CD47-signal regulatory protein- $\alpha$ (SIRP $\alpha$ ) interactions form a barrier for antibody-mediated tumor cell destruction. Proc Natl Acad Sci U S A 2011;108:18342-7.

128 Yu XY, Qiu WY, Long F, Yang XP, Zhang C, et al. A novel fully human anti-CD47 antibody as a potential therapy for human neoplasms with good safety. Biochimie 2018;151:54-66.

129. Park SC, Nguyen NT, Eun JR, Zhang Y, Jung YJ, et al. Identification of Cancer Stem Cell Subpopulations of CD34(+) PLC/PRF/5 That Result in Three Types of Human Liver Carcinomas. Stem Cells Dev 2015;24:1008-1021.

130 Crosby HA, Kelly DA, Strain AJ. Human hepatic stem-like cells isolated using c-kit or CD34 can differentiate into biliary epithelium. Gastroenterology 2001;120:534-44.

131. Zeng C, Zhang Y, Park SC, Eun JR, Nguyen NT, et al. CD34(+) Liver Cancer Stem Cells Were Formed by Fusion of Hepatobiliary Stem/ Progenitor Cells with Hematopoietic Precursor-Derived Myeloid Intermediates. 2015;24:2467-78.

132 Fujio K, Hu Z, Evarts RP, Marsden ER, Niu CH, et al. Coexpression of stem cell factor and c-kit in embryonic and adult liver. Exp Cell Res 1996;224:243-50.

133 Rojas A, Zhang P, Wang Y, Foo WC, Muñoz NM, et al. A positive TGF- $\beta / c-K I T$ feedback loop drives tumor progression in advanced primary liver cancer. Neoplasia 2016;18:371-86.

134 Al-Shafie TA, Ismail A, Ashmawy AM, Elsayed AM, El-Houseini M. Inhibition of c-kit in late cirrhosis may restore TGF- $\beta$ inhibitory effect on somatic liver stem cells and prevent development of hepatocellular carcinoma. Life Sciences 2014;11.

135 Yan W, Zhu Z, Pan F, Huang A, Dai GH. Overexpression of c-kit (CD117), relevant with microvessel density, is an independent survival prognostic factor for patients with HBV-related hepatocellular carcinoma. Onco Targets Ther 2018;11:1285-92.

136 Ashmun RA, Look AT. Metalloprotease activity of CD13/aminopeptidase N on the surface of human myeloid cells. Blood 1990;75:462-9.

137 Hashida H, Takabayashi A, Kanai M, Adachi M, Kondo K, et al. Aminopeptidase N is involved in cell motility and angiogenesis: its clinical significance in human colon cancer. Gastroenterology 2002;122:376-86.

138 Liu LL, Fu D, Ma Y, Shen XZ. Development. The power and the promise of liver cancer stem cell markers. Stem Cells Dev 2011;20:202330.

139 Petrovic N, Schacke W, Gahagan JR, O'Conor CA, Winnicka B, et al. CD13/APN regulates endothelial invasion and filopodia formation. Blood 2007;110:142-50.

140. Nagano H, Ishii H, Marubashi S, Haraguchi N, Eguchi H, et al. Novel therapeutic target for cancer stem cells in hepatocellular carcinoma. J Hepatobiliary Pancreat Sci 2012;19:600-605.

141. Kim HM, Haraguchi N, Ishii H, Ohkuma M, Okano M, et al. Increased CD13 expression reduces reactive oxygen species, promoting survival of liver cancer stem cells via an epithelial-mesenchymal transition-like phenomenon. Ann Surg Oncol 2012;19:539-48.

142 Yamashita M, Wada H, Eguchi H, Ogawa H, Yamada D, et al. A CD13 inhibitor, ubenimex, synergistically enhances the effects of anticancer drugs in hepatocellular carcinoma. Int J Oncol 2016;49:89-98.

143 Ji J, Wang XW. Clinical implications of cancer stem cell biology in hepatocellular carcinoma. Semin Oncol 2012;39:461-72.

144 Athanassiadou P, Grapsa D, Gonidi M, Athanassiadou AM, Tsipis A, et al. CD24 expression has a prognostic impact in breast carcinoma. Pathol Res Pract 2009;205:524-33.

145 Huang LR, Hsu HC. Cloning and expression of CD24 gene in human hepatocellular carcinoma: a potential early tumor marker gene correlates with p53 mutation and tumor differentiation. Cancer Res 1995;55:4717-21.

146 Liu AY, Cai Y, Mao Y, Lin Y, Zheng H, et al. Twist2 promotes self-renewal of liver cancer stem-like cells by regulating CD24. Carcinogenesis 2014;35:537-45.

147 García K, Nabhani T, García J. The calcium channel $\alpha 2 / \delta 1$ subunit is involved in extracellular signalling. J Physiol 2010;586:727-38.

148 Huang $\mathrm{C}$, Li Y, Zhao W, Zhang A, Lu C, et al. $\alpha 2 \delta 1$ may be a potential marker for tumor stem cell in laryngeal squamous cell carcinoma. 
Cancer Biomark 2019;24:97-107.

149 Sui X, Geng JH, Li YH, Zhu GY, Wang WH. Calcium channel $\alpha 2 \delta 1$ subunit (CaCna2D1) enhances radioresistance in cancer stem-like cells in non-small cell lung cancer cell lines. Cancer Manag Res 2018;10:5009-18.

150 Zhang Y, Zhao W, Han H, Li S, Chen D, et al. MicroRNA-31 suppresses the self-renewal capability of $\alpha 2 \delta 1+$ liver tumor-initiating cells by targetingISL1. Oncotarget 2017;8:87647-57.

151 Roskams T, De Vos R, Van Eyken P, Myazaki H, Van Damme B, et al. Hepatic OV-6 expression in human liver disease and rat experiments: evidence for hepatic progenitor cells in man. J Hepatol 1998;29:455-63.

152 Yang W, Yan HX, Chen L, Liu Q, He YQ, et al. Wnt/beta-catenin signaling contributes to activation of normal and tumorigenic liver progenitor cells. Cancer Res 2008;68:4287-95.

153. Tanimizu N, Nishikawa M, Saito H, Tsujimura T, Miyajima A. Isolation of hepatoblasts based on the expression of Dlk/Pref-1. 2003;116:1775-86.

154 Huang J, Zhang X, Zhang M, Zhu JD, Zhang YL, et al. Up-regulation of DLK1 as an imprinted gene could contribute to human hepatocellular carcinoma. Carcinogenesis 2007;28:1094-103.

$155 \mathrm{Xu}$ X, Liu RF, Zhang X, Huang LY, Chen F, et al. DLK1 as a potential target against cancer stem/progenitor cells of hepatocellular carcinoma. Mol Cancer Ther 2012;11:629-38.

156 Stosiek P, Kasper M, Karsten U. Expression of cytokeratin 19 during human liver organogenesis. Liver 2010;10:59-63.

157 Kawai T, Yasuchika K, Seo S, Higashi T, Ishii T, et al. Identification of keratin 19-positive cancer stem cells associating human hepatocellular carcinoma using 18f-fluorodeoxyglucose positron emission tomography. Clin Cancer Res 2017;23:1450-60.

158 Govaere O, Petz M, Wouters J, Vandewynckel YP, Scott EJ, et al. The PDGFR $\alpha$-laminin B1-keratin 19 cascade drives tumor progression at the invasive front of human hepatocellular carcinoma. Oncogene 2017;36:6605-16.

159 Rhee H, Kim HY, Choi JH, Woo HG, Yoo JE, et al. Keratin 19 expression in hepatocellular carcinoma is regulated by fibroblast-derived HGF via a MET-ERK1/2-AP1 and SP1 axis. Cancer Res 2018;78:1619-31.

160 Govaere O, Komuta M, Berkers J, Spee B, Janssen C, et al. Keratin 19: a key role player in the invasion of human hepatocellular carcinomas. Gut 2014;63:674-85.

161 Kim H, Choi GH, Na DC, Ahn EY, Kim GI, et al. Human hepatocellular carcinomas with "Stemness"-related marker expression: keratin 19 expression and a poor prognosis. Hepatology 2011;54:1707-17.

162 Bae JS, Choi HN, Noh SJ, Park BH, Jang KY, et al. Expression of K19 and K7 in dysplastic nodules and hepatocellular carcinoma. Oncol Lett 2012;4:213-20.

163 Fatourou E, Koskinas J, Karandrea D, Palaiologou M, Syminelaki T, et al. Keratin 19 protein expression is an independent predictor of survival in human hepatocellular carcinoma. Eur J Gastroenterol Hepatol 2015;27:1094-102.

164 Kowalik MA, Sulas P, Ledda-Columbano GM, Giordano S, Columbano A, et al. Cytokeratin-19 positivity is acquired along cancer progression and does not predict cell origin in rat hepatocarcinogenesis. Oncotarget 2015;6:38749-63.

165 de Lau W, Barker N, Low TY, Koo BK, Li VS, et al. Lgr5 homologues associate with Wnt receptors and mediate R-spondin signalling. Nature 2011;476:293-7.

166 Jaks V, Barker N, Kasper M, van Es JH, Snippert HJ, et al. Lgr5 marks cycling, yet long-lived, hair follicle stem cells. Nat Genet 2008;40:1291-9.

167 Barker N, Huch M, Kujala P, van de Wetering M, Snippert HJ, et al. Lgr5(+ve) stem cells drive self-renewal in the stomach and build long-lived gastric units in vitro. Cell Stem Cell 2010;6:25-36.

168 Plaks V, Brenot A, Lawson D, Linnemann JR, Vankappel EC, et al. Lgr5 -Expressing Cells Are Sufficient and Necessary for Postnatal Mammary Gland Organogenesis. Cell Rep 2013;3:70-8.

169 Ng A, Tan S, Singh G, Rizk P, Swathi Y, et al. Lgr5 marks stem/progenitor cells in ovary and tubal epithelia. Nat Cell Biol 2014;16:74557.

170 Huch M, Bonfanti P, Boj SF, Sato T, Loomans CJ, et al. Unlimited in vitro expansion of adult bi-potent pancreas progenitors through the Lgr5/R-spondin axis. EMBO J 2013;32:2708-21.

171 Leushacke M, Si HT, Wong A, Swathi Y, Hajamohideen A, et al. Lgr5-expressing chief cells drive epithelial regeneration and cancer in the oxyntic stomach. Nat Cell Biol 2017;19:774-86.

172 Barker N, Van Es JH, Kuipers J, Kujala P, Van Den Born M, et al. Identification of stem cells in small intestine and colon by marker gene Lgr5. Nature 2007;449:1003-7.

173 Shimokawa M, Ohta Y, Nishikori S, Matano M, Takano A, et al. Visualization and targeting of LGR5+ human colon cancer stem cells. Nature 2017;547:187-92.

174 de Lau W, Peng WC, Gros P, Clevers H. The R-spondin/Lgr5/Rnf43 module: regulator of Wnt signal strength. Genes Dev 2014;28:30516.

175 Lin Y, Fang ZP, Liu HJ, Wang LJ, Cheng Z, et al. HGF/R-spondin1 rescues liver dysfunction through the induction of Lgr5+liver stem cells. Nat Commun 2017;8:1175.

176 Effendi K, Yamazaki K, Fukuma M, Sakamoto M. Overexpression of Leucine-Rich Repeat-Containing G Protein-Coupled Receptor 5 (LGR5) Represents a Typical Wnt/B-Catenin Pathway-Activated Hepatocellular Carcinoma. Liver Cancer 2014;3:451-7.

177 Lei ZJ, Wang J, Xiao HL, Guo Y, Wang T, et al. Lysine-specific demethylase 1 promotes the stemness and chemoresistance of Lgr5(+) liver cancer initiating cells by suppressing negative regulators of $\beta$-catenin signaling. Oncogene 2015;34:3188-98.

$178 \mathrm{Lu} \mathrm{B}$, Huang X, Mo J, Zhao W. Drug delivery using nanoparticles for cancer stem-like cell targeting. Front Pharmacol 2016;7:84.

179 Wang X, Low XC, Hou W, Abdullah LN, Toh TB, et al. Epirubicin-adsorbed nanodiamonds kill chemoresistant hepatic cancer stem 
cells. ACS Nano 2014;8:12151-66.

180 Wang Z, Tan J, Mcconville C, Kannappan V, Tawari PE, et al. Poly lactic-co-glycolic acid controlled delivery of disulfiram to target liver cancer stem-like cells. Nanomedicine 2017;13:641-57.

181 Gao H, Li K, Tu H, Pan X, Jiang H, et al. Development of T cells redirected to glypican-3 for the treatment of hepatocellular carcinoma. Clin Cancer Res 2014;20:6418-28.

182 Pan QZ, Pan K, Wang QJ, Weng DS, Zhao JJ, et al. Annexin A3 as a potential target for immunotherapy of liver cancer stem-like cells. Stem Cells 2015;33:354-66.

183 Xu X, Xing B, Hu M, Xu Z, Xie Y, et al. Recurrent hepatocellular carcinoma cells with stem cell-like properties: possible targets for immunotherapy. Cytotherapy 2010;12:190-200.

184 Jung JW, Yoon SM, Kim S, Jeon YH, Yoon BH, et al. Bone morphogenetic protein-9 is a potent growth inhibitor of hepatocellular carcinoma and reduces the liver cancer stem cells population. Oncotarget 2016;7:73754-68.

185 Llovet JM, Ricci S, Mazzaferro V, Hilgard P, Gane E, et al. Sorafenib in advanced hepatocellular carcinoma. N Engl J Med 2008;359:37890.

186 Kudo M, Finn RS, Qin S, Han KH, Ikeda K, et al. Lenvatinib versus sorafenib in first-line treatment of patients with unresectable hepatocellular carcinoma: a randomised phase 3 non-inferiority trial. Lancet 2018;391:1163-73.

187 Bruix J, Qin S, Merle P, Granito A, Huang YH, et al. Regorafenib for patients with hepatocellular carcinoma who progressed on sorafenib treatment (RESORCE): a randomised, double-blind, placebo-controlled, phase 3 trial. Lancet 2016;389:56-66.

188 Sprinzl MF, Galle PR. Current progress in immunotherapy of hepatocellular carcinoma. J Hepatol 2017;66:482-4.

189 El-Khoueiry AB, Sangro B, Yau T, Crocenzi TS, Kudo M, et al. Nivolumab in patients with advanced hepatocellular carcinoma (CheckMate 040): an open-label, non-comparative, phase 1/2 dose escalation and expansion trial. Lancet 2017;389:2492-502.

190 Zhu AX, Finn RS, Edeline J, Cattan S, Ogasawara S, et al. Pembrolizumab in patients with advanced hepatocellular carcinoma previously treated with sorafenib (KEYNOTE-224): a non-randomised, open-label phase 2 trial. Lancet Oncol 2018;19:940-52.

191 Rycaj K, Tang DG. Cancer stem cells and radioresistance. Int J Radiat Biol 2014;90:615-21.

192 Morrison R, Schleicher SM, Sun Y, Niermann KJ, Kim S, et al. Targeting the mechanisms of resistance to chemotherapy and radiotherapy with the cancer stem cell hypothesis. J Oncol 2011;2011:941876.

193 Sun R, Liu Y, Li SY, Shen S, Du XJ, et al. Co-delivery of all-trans-retinoic acid and doxorubicin for cancer therapy with synergistic inhibition of cancer stem cells. Biomaterials 2015;37:405-14.

194 Singh A, Settleman J. EMT, cancer stem cells and drug resistance: an emerging axis of evil in the war on cancer. Oncogene 2010;29:474151.

195 Liu C, Liu L, Shan J, Shen J, Xu Y, et al. Histone deacetylase 3 participates in self-renewal of liver cancer stem cells through histone modification. Cancer Lett 2013;339:60-9.

196 Fang L, Zhang HB, Li H, Fu Y, Yang GS. miR-548c-5p inhibits proliferation and migration and promotes apoptosis in CD90(+) HepG2 cells. Radiol Oncol 2012;46:233-41. 